\title{
The phylogenetic position of the solitary zoanthid genus Sphenopus (Cnidaria: Hexacorallia)
}

\author{
James D. Reimer ${ }^{1,2,7}$, Meifang Lin ${ }^{3}$, Takuma Fujii ${ }^{4}$, David J.W. Lane ${ }^{5}$, Bert W. Hoeksema ${ }^{6}$ \\ ${ }^{1}$ Molecular Invertebrate Systematics and Ecology Laboratory, Rising Star Program, Transdisciplinary Research \\ Organization for Subtropical Island Studies (TRO-SIS), University of the Ryukyus, Senbaru 1, Nishihara, Okinawa \\ 903-0213, Japan \\ ${ }^{2}$ Marine Biodiversity Research Program, Institute of Biogeosciences, Japan Agency for Marine-Earth Science and \\ Technology (JAMSTEC), 2-15 Natsushima, Yokosuka, Kanagawa 237-0061, Japan \\ ${ }^{3}$ Biodiversity Research Center, Academia Sinica, Nangkang, Taipei 115, Taiwan \\ ${ }^{4}$ Molecular Invertebrate Systematics and Ecology Laboratory, Graduate School of Engineering and Sciences, \\ University of the Ryukyus, Senbaru 1, Nishihara, Okinawa 903-0213, Japan \\ ${ }^{5}$ Department of Biology, Faculty of Science, Universiti Brunei Darussalam, Jalan Tungku Link BE1410, Brunei \\ Darussalam \\ ${ }^{6}$ Department of Marine Zoology, Netherlands Centre for Biodiversity Naturalis, PO Box 9517, 2300 RA Leiden, \\ The Netherlands \\ ${ }^{7}$ E-mail: jreimer@sci.u-ryukyu.ac.jp
}

Key words: Anthozoa, azooxanthellate, biodiversity, DNA marker, free-living, marine invertebrate, monostomatous, Sphenopidae

\begin{abstract}
The zoanthid genus Sphenopus (Cnidaria: Anthozoa: Zoantharia), like many other brachycnemic zoanthids, is found in shallow subtropical and tropical waters, but is uniquely unitary (solitary, monostomatous), azooxanthellate, and free-living. With sparse knowledge of its phylogenetic position, this study examines the phylogenetic position of Sphenopus within the family Sphenopidae utilizing specimens from southern Taiwan and Brunei collected in 1999-2011, and furthermore analyzes the evolution of its unique character set via ancestral state reconstruction analyses. Phylogenetic analyses surprisingly show Sphenopus to be phylogenetically positioned within the genus Palythoa, which is colonial (polystomatous), zooxanthellate, and attached to solid substrate. Ancestral state reconstruction strongly indicates that the unique characters of Sphenopus have evolved recently within Palythoa and only in the Sphenopus lineage. These results indicate that zoanthid body plans can evolve with rapidity, as in some other marine invertebrates, and that the traditional definitions of zoanthid genera may need reexamination.
\end{abstract}

\section{Contents}

Introduction

Material and methods 43

Specimen collection

Specimen identification

DNA extraction, PCR amplification, sequencing

Phylogenetic analyses

Ancestral character state reconstruction

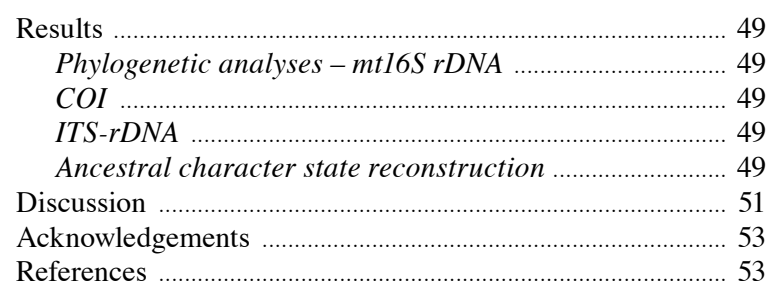

\section{Introduction}

The zoanthids are an order (=Zoantharia, or Zoanthidea) of benthic cnidarians related to scleractinian corals and sea anemones within the subclass Hexacorallia, class Anthozoa. Similar to order Scleractinia, zoanthids are generally colonial (modular or polystomatous), but unlike these stony corals they are not calcifiers; instead most zoanthids incorporate sand and other detritus into their body wall to contribute to their structure. Zoanthids in the genus Palythoa can be up to $60 \%$ encrustation by weight (Haywick and Mueller, 1997). This encrustation impedes internal examination of zoanthids, making observation of the sphincter muscles, mesenteries, and other characters difficult (Reimer et al., 2010). Furthermore, many zoanthid species show much intraspecific morphological variation, compounding the difficulty of identification (Muirhead and Ryland, 1985; Burnett et al., 

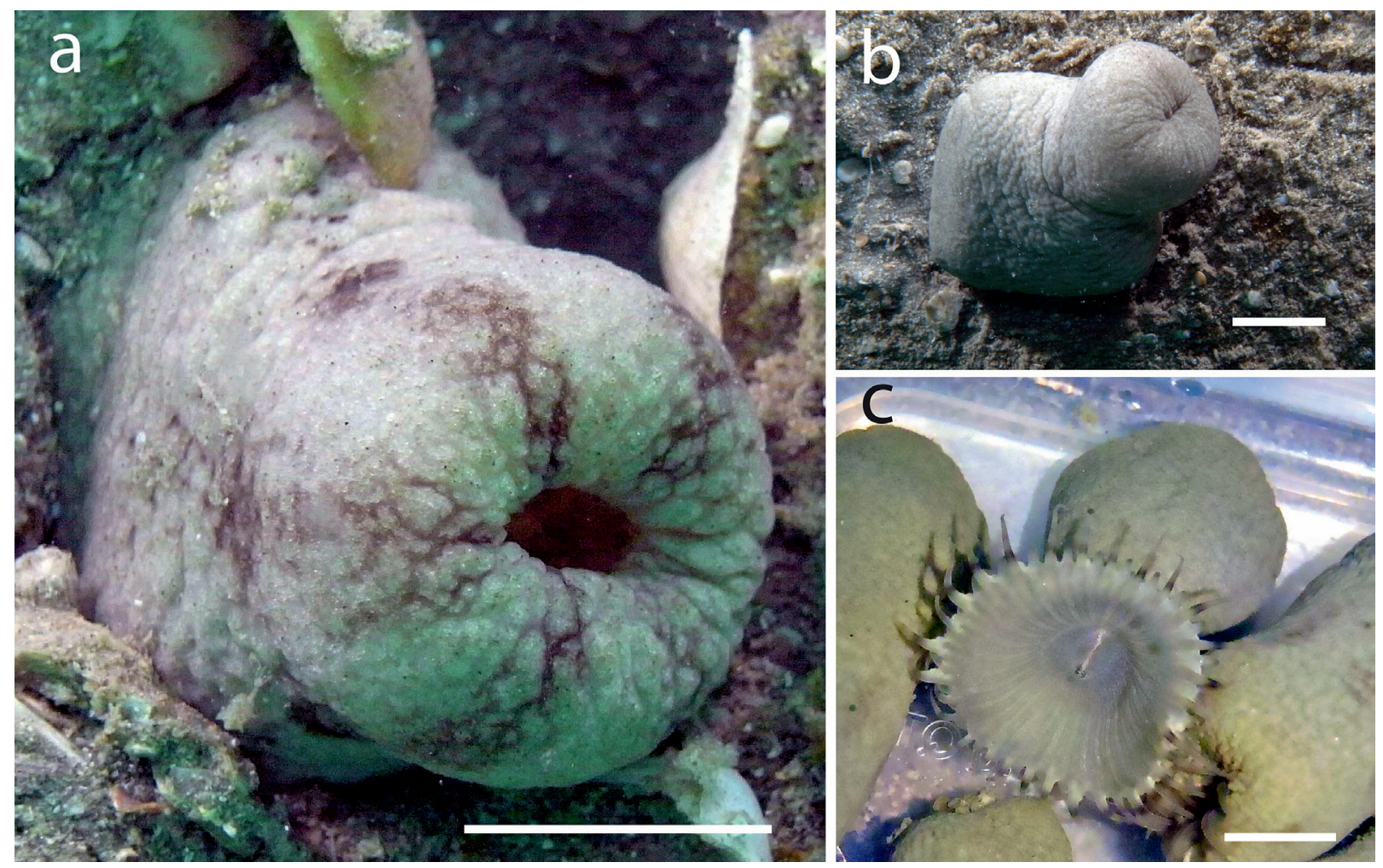

Fig. 1. a-c. In situ images of Sphenopus marsupialis specimens from Brunei. Note sandy sediment habitat background in a and b, and open oral disk in c. For specimen and collection information refer to Table 1. Scale $=$ approx. $1 \mathrm{~cm}$.

Table 1. Specimens of Sphenopus marsupialis utilized in this study, collection details, and GenBank Accession Numbers for DNA sequences. Abbreviations: $\mathrm{n} / \mathrm{a}=$ not available, or not acquired; MISE = Molecular Systematics and Ecology laboratory (U. Ryukyus), BRCAS = Biodiversity Research Center Academia Sinica (Taiwan), DJWL = DJW Lane, BWH = BW Hoeksema.

\begin{tabular}{|c|c|c|c|c|c|c|c|c|}
\hline 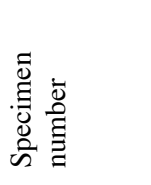 & 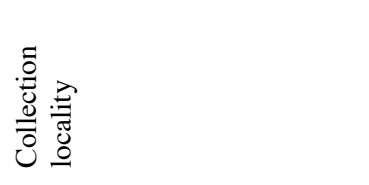 & 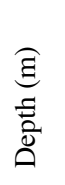 & $\begin{array}{l}\stackrel{0}{0} \\
\stackrel{0}{0} \\
\stackrel{0}{0}\end{array}$ & $\begin{array}{l}\widehat{\hat{n}} \\
\frac{0}{0} \\
\frac{0}{0} \\
0\end{array}$ & $\begin{array}{l}\overleftrightarrow{z} \\
\text { ă } \\
\text { bै } \\
\vec{\Xi} \\
\vec{z}\end{array}$ & $\overline{0}$ & 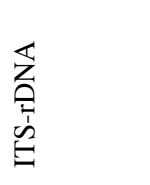 & 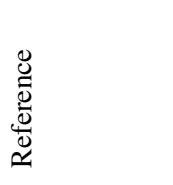 \\
\hline T1 (MISE) & Shitzwan, Taiwan & $\mathrm{n} / \mathrm{a}$ & 1999 & BRCAS & $\mathrm{n} / \mathrm{a}$ & $\mathrm{n} / \mathrm{a}$ & $\mathrm{n} / \mathrm{a}$ & This study \\
\hline S1 & SW of Pelong Rocks, Brunei & 13 & 23.iv.2011 & DWJL, BWH & JQ323164 & JQ323180 & $\mathrm{n} / \mathrm{a}$ & This study \\
\hline S2 & SW of Pelong Rocks, Brunei & 13 & 23.iv.2011 & DWJL, BWH & JQ323165 & JQ323177 & $\mathrm{n} / \mathrm{a}$ & This study \\
\hline S3 & SW of Pelong Rocks, Brunei & 13 & 23.iv.2011 & DWJL, BWH & JQ323163 & JQ323174 & JQ323159 & This study \\
\hline S4 & SW of Pelong Rocks, Brunei & 13 & 23.iv.2011 & DWJL, BWH & JQ323166 & JQ323170 & JQ323158 & This study \\
\hline S5 & SW of Pelong Rocks, Brunei & 13 & 23.iv.2011 & DWJL, BWH & JQ323160 & JQ323173 & $\mathrm{n} / \mathrm{a}$ & This study \\
\hline S6 & SW of Pelong Rocks, Brunei & 13 & 23.iv.2011 & DWJL, BWH & $\mathrm{n} / \mathrm{a}$ & $\mathrm{n} / \mathrm{a}$ & $\mathrm{n} / \mathrm{a}$ & This study \\
\hline S7 & SW of Pelong Rocks, Brunei & 13 & 23.iv.2011 & DWJL, BWH & JQ323169 & JQ323171 & JQ323157 & This study \\
\hline S8 & SW of Pelong Rocks, Brunei & 13 & 23.iv.2011 & DWJL, BWH & JQ323168 & JQ323172 & JQ323156 & This study \\
\hline S9 & SW of Pelong Rocks, Brunei & 13 & 23.iv.2011 & DWJL, BWH & $\mathrm{n} / \mathrm{a}$ & $\mathrm{n} / \mathrm{a}$ & $\mathrm{n} / \mathrm{a}$ & This study \\
\hline S10 & SW of Pelong Rocks, Brunei & 13 & 23.iv.2011 & DWJL, BWH & JQ323162 & JQ323178 & $\mathrm{n} / \mathrm{a}$ & This study \\
\hline S11 & SW of Pelong Rocks, Brunei & 13 & 23.iv.2011 & DWJL, BWH & JQ323167 & JQ323176 & $\mathrm{n} / \mathrm{a}$ & This study \\
\hline S12 & SW of Pelong Rocks, Brunei & 13 & 23.iv.2011 & DWJL, BWH & JQ323161 & JQ323175 & $\mathrm{n} / \mathrm{a}$ & This study \\
\hline I1-I3 & $\begin{array}{l}\text { Bintan, Riau Archipelago, } \\
\text { Indonesia }\end{array}$ & $\mathrm{n} / \mathrm{a}$ & vi.1995 & DWJL & $\mathrm{n} / \mathrm{a}$ & $\mathrm{n} / \mathrm{a}$ & $\mathrm{n} / \mathrm{a}$ & This study \\
\hline Not given & Suao, Taiwan & $\mathrm{n} / \mathrm{a}$ & $\mathrm{n} / \mathrm{a}$ & BRCAS & $\mathrm{n} / \mathrm{a}$ & $\mathrm{n} / \mathrm{a}$ & AB441420 & $\begin{array}{l}\text { Fukami et al. } \\
2008\end{array}$ \\
\hline
\end{tabular}


1995; Reimer et al., 2004). Thus, a clear understanding of the species richness of this order has not yet been achieved. Recent examinations of shallow-water zoanthids (Suborder Brachycnemina) utilizing allozymes (Burnett et al., 1997) and DNA phylogenetic analyses (Reimer et al., 2006a, b, 2007b, 2008) have led to speculation that many currently described species in the literature are actually inadvertent redescriptions (Burnett et al., 1997), and it is possible that species numbers in the coral reef genera Zoanthus, Isaurus, and Palythoa are lower than currently believed. Additionally, other recent phylogenetic examinations have questioned the current taxonomic placement of lesserknown coral reef zoanthid genera such as Acrozoanthus (Reimer et al., 2011b) and Neozoanthus (Reimer et al., 2011a).

The phylogenetic placement of one brachycnemic zoanthid genus, Sphenopus, has not yet been comprehensively examined. Sphenopus was originally defined and described by Steenstrup (1856), and is placed together with Palythoa in the family Sphenopidae. Unlike most other zoanthids, Sphenopus is always unitary (as defined by Ryland and Lancaster (2003); = monostomatous, solitary, not colonial or modular, unless budding), and usually not attached to any substrate (i.e., free-living). Instead, the large polyps (up to $3 \mathrm{~cm}$ in diameter, $4.5 \mathrm{~cm}$ in length) are generally rounded and bulbous or anchored at the aboral end and are found partially embedded in sandy, coral reef environments. Specimens have been reported in popular handbooks and field guides from various localities, such as the Seychelles (Den Hartog, 1997), Malaysia and Indonesia (Erhardt and Knop, 2005), Papua New Guinea (Colin and Arneson, 1995) and eastern Australia (Zann, 1980). They possess some limited mobility (Soong et al., 1999) and their mode of nutrition is suspension feeding. Aside from some investigations on reproductive ecology (Soong et al., 1999) and use in one phylogenetic study as an outgroup (Fukami et al., 2008), very little is known about Sphenopus phylogeny and diversity.

In this study, we examine the phylogenetic position of Sphenopus with specimens of S. marsupialis (Gmelin 1791), the type species of this genus, from both Taiwan and Brunei, and generate phylogenetic trees using sequences of the mitochondrial DNA markers cytochrome oxidase subunit 1 (COI), 16S rDNA (mt 16S rDNA), and the nuclear internal transcribed spacer region (ITS-rDNA). We also attempt to map both the evolution/devolution of symbioses with Symbiodinium and the unitary and free-living body plan within the suborder Brachycnemina by ancestral state reconstruction. Our results lead us to reconsider the definition of Palythoa and Sphenopus, and demonstrate the relative rapidity in which radically different body plans and strategies can evolve in zoanthids.

\section{Material and methods}

\section{Specimen collection}

Sphenopus specimens from Brunei $(\mathrm{n}=12)$ were collected on $23^{\text {rd }}$ April 2011 at a sandy/muddy bank (depth approximately $13 \mathrm{~m}) 1.5 \mathrm{~km}$ southwest of Pulau Pelong-Pelongan (Pelong Rocks) and $3.5 \mathrm{~km}$ from the Brunei coastline ( $\left.5^{\circ} 04^{\prime} 10.08^{\prime \prime} \mathrm{N}, 115^{\circ} 02^{\prime} 35.1^{\prime \prime} \mathrm{E}\right)$. Collected specimens were photographed in situ and subsequently in a dish of seawater, with the polyp disc allowed to expand (Fig. 1). Preservation was carried out using $70 \%$ analytical grade ethanol. A specimen from Taiwan ( $\mathrm{n}=1)$ was collected in 1999 at Shitzwan

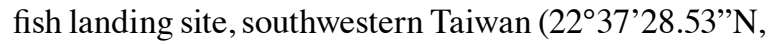
$\left.120^{\circ} 15^{\prime} 39.08^{\prime \prime} \mathrm{E}\right)$ from a bottom trawl sample, depth unknown, and preserved in 70\% ethanol. Three additional specimens from Indonesia collected in 1995 have been included in the specimen list (Table 1) to increase information on the distribution of this species, but were not examined in this study.

\section{Specimen identification}

Currently the genus contains three described species (Reimer, 2011), the type species $S$. marsupialis (Gmelin, 1791), S. arenaceus Hertwig, 1882 and S.pedunculatus Hertwig, 1888. The latter two have not been reported on for over 80 years. The type species $S$. marsupialis, is worldwide in distribution (Soong et al., 1999), including reports in the Pacific from the Great Barrier Reef (Burnett et al., 1997) and Taiwan (Soong et al., 1999). If $S$. marsupialis in fact consists of several sibling species, these would likely be very closely related (Soong et al., 1999), and to date no evidence of genetic differentiation among $S$. marsupialis specimens has been found (Burnett et al., 1997). This species has a rounded bottom portion, and is earthen-gray in colour (Hertwig, 1882).

Sphenopus arenaceus Hertwig, 1882 (not mentioned since Pax, 1924), is similar to S. marsupialis in being unitary and free-living, but it has a rusty red colour, while S. pedunculatus Hertwig, 1888 (not mentioned since Delage and Hérouard, 1901) is heavily furrowed 


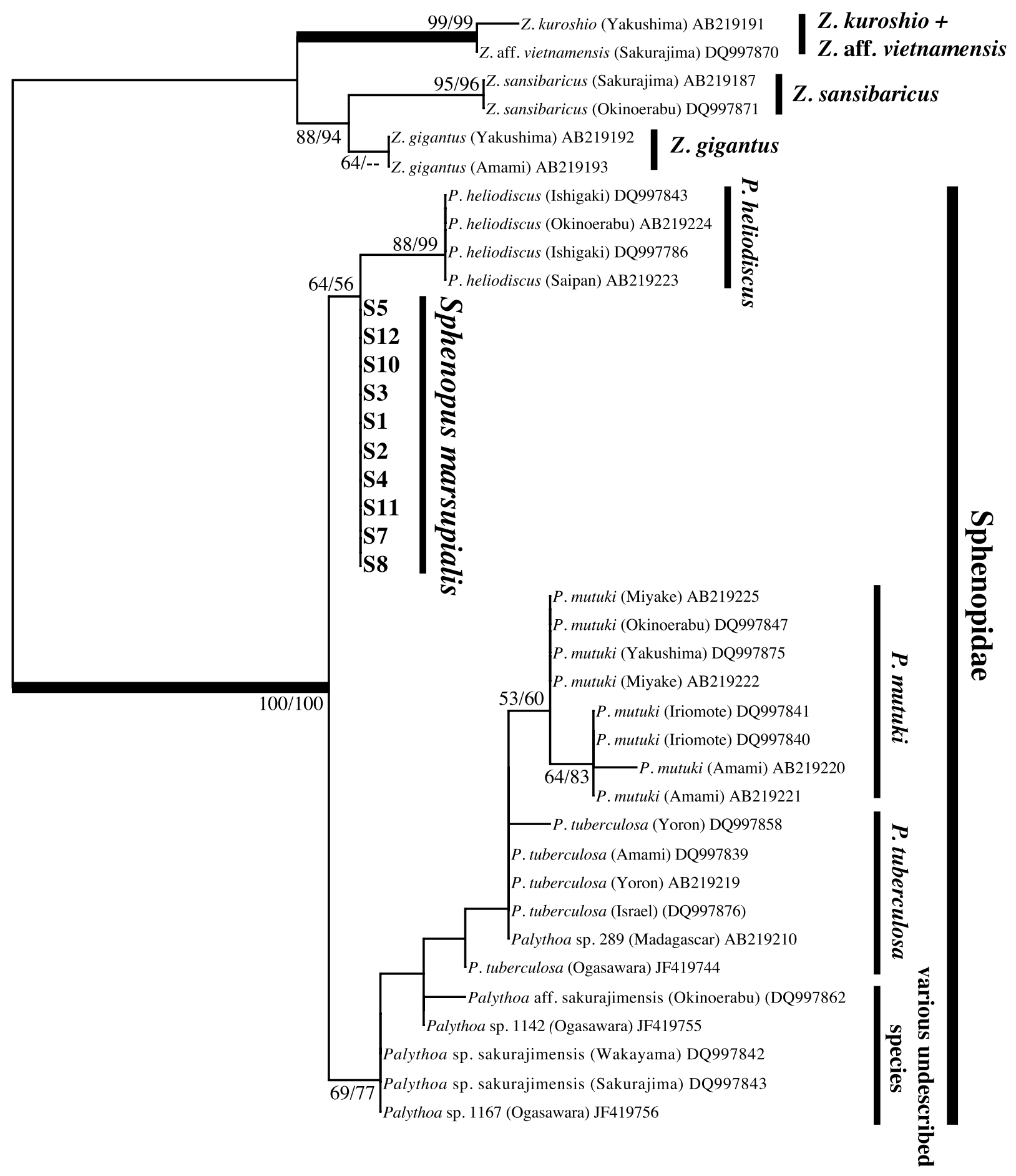

\section{$\longmapsto 0.002$ substitutions/site $\quad$ ML/NJ}

Fig. 2. Maximum likelihood (ML) tree of an alignment of mitochondrial 16S ribosomal DNA sequences for zoanthid specimens. Values at branches represent ML and neighbor-joining (NJ) bootstrap values, respectively. Sequences newly obtained in this study in bold. Thick branches indicate Bayesian posterior probabilities $>0.95$. Sequences from previous studies in regular font with GenBank Accession Number. For specimen information see Table 1. 
and attached with a long 'foot' or 'stalk' to small pieces of stone, as in specimens illustrated by Erhardt and Knop (2005). All three species are solitary, azooxanthellate, free-living and live in sandy environments.

Specimens in this study best fit the description of $S$. marsupialis (solitary, not attached to substrate, sand encrustation, inhabiting sandy/muddy bottoms, azooxanthellate, earthy-gray in colour) and were thus identified as $S$. marsupialis.

Specimens collected from Brunei in April 2011 have been deposited in the collection of the Netherlands Centre for Biodiversity Naturalis at Leiden (catalogue number RMNH.Coel.40119). Additional material, collected on 30 November 2011 from the same location, is deposited in the Universiti Brunei Darussalam Department of Biology reference collection (catalogue number UBDM.6.00001).

\section{DNA extraction, PCR amplification, sequencing}

Genomic DNA was extracted from portions of specimens either using spin-column Dneasy Animal Extraction protocol (Qiagen, Santa Clarita, CA) according to the manufacturer's instructions, or by following a guanidine extraction protocol as described in Sinniger et al. (2010). PCR amplification using template genomic DNA was conducted using HotStarTaq DNA polymerase (Qiagen) according to the manufacturer's instructions. Mitochondrial 16S ribosomal DNA (mt 16S rDNA), cytochrome oxidase subunit 1 (COI) and nuclear internal transcribed spacer region (ITS-rDNA) were amplified using primers and amplification conditions following Sinniger et al. (2005, 2010), Reimer et al. (2007a), and Reimer et al. (2007b), respectively.

Amplified products were visualized by $1.0 \%$ agarose gel electrophoresis, and positive PCR products were treated with Exonuclease I and Shrimp Alkaline Phosphatate (Takara) prior to sequencing reactions. Sequencing was performed by MacroGen Japan (Tokyo).

\section{Phylogenetic analyses}

New sequences obtained in this study were deposited in GenBank (accession numbers JQ323156-JG323180). Sequences of all three DNA markers were aligned with publically available sequences of family Sphenopidae (Palythoa), with Zoanthus (Zoanthidae) sequences utilized as outgroups for mt16S rDNA and COI, as the monophylies of these two families and their sister-group relationship has previously been demonstrated (Sinniger et al., 2005). For the ITS-rD-
NA alignment, only Sphenopidae sequences were included, as this marker has been shown to have high variability in Zoanthus (Reimer et al., 2007c).

All alignments were constructed manually based on previously published and publically available Brachycnemina (primarily Palythoa and Zoanthus) sequence alignments, inspected by eye, and any ambiguous sites in the alignments were removed from the dataset prior to phylogenetic analyses. Three alignment datasets were generated: 1) 757 sites of 39 sequences (mt 16S rDNA), 2) 462 sites of 35 sequences (COI) and 3) 955 sites of 72 sequences (ITS-rDNA). Alignment data sets are available from the corresponding author and at the homepage http://web.me.com/ miseryukyu/.

For the phylogenetic analyses of the data sets, the same methods were independently applied. Alignments were subjected to analyses with the maximum likelihood (ML) with PhyML (Guindon and Gascuel, 2003) and neighbour-joining (NJ) methods. PhyML was performed using an input tree generated by BIONJ with the general time-reversible model (Rodriguez et al., 1990) of nucleotide substitution incorporating a discrete gamma distribution (eight categories) (GTR+). The discrete gamma distribution and base frequencies of the model were estimated from the dataset. PhyML bootstrap trees (1000 replicates) were constructed using the same parameters as the individual ML tree. The distances were calculated using a Kimura's 2-parameter model (Kimura, 1980). Support for $\mathrm{NJ}$ branches was tested by bootstrap analysis (Felsenstein, 1985) of 1000 replicates. CLC Free Workbench 3.0 (Aarhus, Denmark) was used for NJ phylogenetic analyses (1000 replicates).

Bayesian trees were made by Mr. Bayes 3.1.2 (Ronquist and Huelsenbeck, 2003) under GTR $+\mathrm{I}+\Gamma$. One cold and three heated Markov chains Monte Carlo (MCMC) with default-chain temperatures were run for 2 million generations, sampling log-likelihoods (InLs), and trees at 100-generation intervals $(20,000 \mathrm{InLs}$ and trees were saved during MCMC). The likelihood plots for COI, mt $16 \mathrm{~S}$ rDNA and ITS-rDNA datasets suggested that MCMC reached the stationary phase after the first 300,000 generations for COI and $\mathrm{mt} 16 \mathrm{~S}$ rDNA (standard deviation of split frequencies $=0.006620$ and 0.004511 , respectively), and after 500,000 million generations for the ITS-rDNA analysis (standard deviation of split frequencies $=0.052928$ ). Thus, the remaining 17,000 trees of COI and $\mathrm{mt} 16 \mathrm{~S}$ rDNA, and the remaining 25,000 trees of ITS-rDNA were used to obtain clade probabilities and branch-length estimates. 


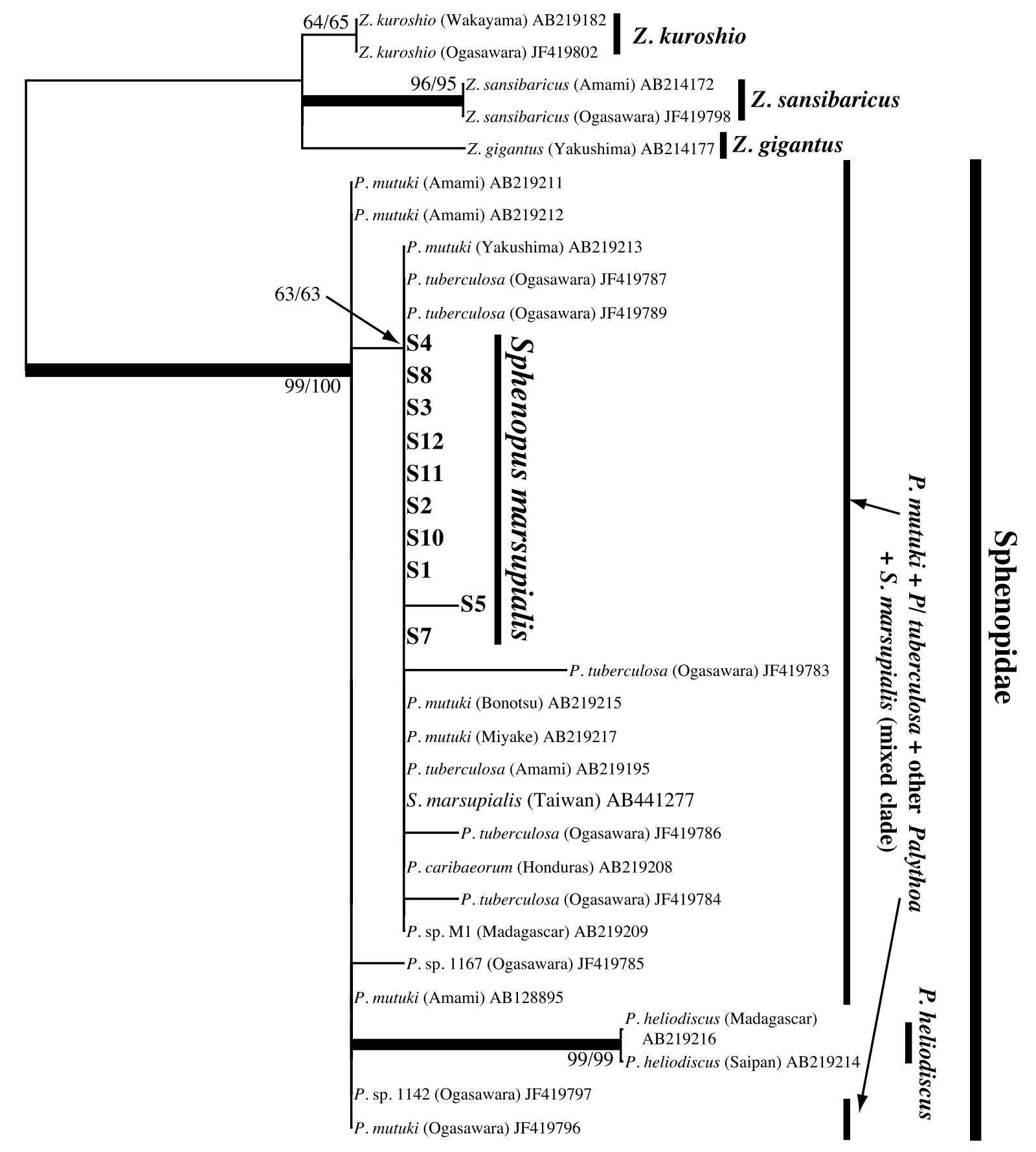

$\longmapsto 0.002$ substitutions/site $\mathrm{ML} / \mathrm{NJ}$

Fig. 3. Maximum likelihood (ML) tree of an alignment of mitochondrial cytochrome oxidase subunit 1 (COI) sequences for zoanthid specimens. Values at branches represent ML and neighbor-joining (NJ) bootstrap values, respectively. Sequences newly obtained in this study in bold. Thick branches indicate Bayesian posterior probabilities $>0.95$. Sequences from previous studies in regular font with GenBank Accession Number. For specimen information see Table 1. 


\section{Ancestral character state reconstruction}

To reconstruct ancestral evolution in Brachycnemina, ancestral character state reconstructions were performed with both ML and maximum parsimony (MP) methods by tracing the character states of colony form and zooxanthellae symbiosis over a 'reduced taxa' $\mathrm{mt}$ 16S rDNA ML tree utilizing Mesquite v.2.7.4 (Maddison and Maddison, 2010). The reduced taxa ML tree contained only one sequence for each species or species group, and consisted of 757 sites in 13 taxa, with the same basic alignment as in the mt $16 \mathrm{~S}$ rDNA alignment in the previous section, with ML analyses also performed as in the previous section. Species' colony form characters were assigned as: 0 (= colonial, attached to some substrate) for all species except S. marsupialis, 1 (= unitary, not attached to substrate/freeliving) for S. marsupialis; and 0 (= zooxanthellate) for all species except $S$. marsupialis, 1 (= azooxanthellate) for S. marsupialis.

\section{Results}

\section{Phylogenetic analyses - mt $16 \mathrm{~S}$ rDNA}

The maximum likelihood (ML) tree resulting from the analysis of the mt $16 \mathrm{~S}$ rDNA alignment showed two clear groups, one consisting of Zoanthus (family Zoanthidae) outgroups, and another clade with Sphenopus and Palythoa (Sphenopidae) sequences (Fig. 2). All acquired S. marsupialis sequences were identical. Support for the Sphenopidae clade was very high (neighbor joining $[\mathrm{NJ}]=100 \%, \mathrm{ML}=100 \%$, Bayesian posterior probability $[$ Bayes] $=1.00$ ). Within Sphenopidae, two subclades were seen. The first consisted of Sphenopus marsupialis (Gmelin, 1793) and Palythoa heliodiscus Ryland and Lancaster, 2003 sequences, but was only weakly supported $(\mathrm{NJ}=56 \%, \mathrm{ML}=$ $64 \%$, Bayes $<0.50$ ), while the second subclade included P. mutuki Haddon and Shackleton, 1891, P. tuberculosa Klunzinger, 1877, P. sp. 'sakurajimensis' sensu Reimer et al. (2007a) and related sequences $(\mathrm{NJ}=$ $77 \%, \mathrm{ML}=69 \%$, Bayes $=0.83$ ).

\section{COI}

The ML tree for COI had a very similar overall topology to the mt 16S rDNA tree, albeit with some small differences (Fig. 3). Again, Zoanthus spp. sequences formed one clear clade, and Sphenopidae (Sphenopus
+ Palythoa) formed another, very highly supported clade $(\mathrm{NJ}=99 \%, \mathrm{ML}=100 \%$, Bayes $=1.00)$. Again, all acquired $S$. marsupialis sequences were identical, except for the sequence from specimen S5, which differed by one base pair. Within the Sphenopidae, resolution was poorer than observed in the mt $16 \mathrm{~S}$ rDNA tree, with three species (S. marsupialis, P. mutuki, $P$. tuberculosa) appearing particularly poorly resolved, i.e., no clear subclades and no strong support values for each species group. All S. marsupialis sequences formed a weakly supported clade $(\mathrm{NJ}=63 \%, \mathrm{ML}=$ $63 \%$, Bayes $=0.87$ ) together with sequences from $P$. mutuki and P.tuberculosa, and most of the S. marsupialis sequences (S1, S2, S3, S7, S8, S10, S11, S12) were identical to many of the P. mutuki and P. tuberculosa sequences, with only S5 being slightly unique to the other S. marsupialis sequences.

\section{ITS-rDNA}

The ML tree for ITS-rDNA was once again similar in overall topology to both mt $16 \mathrm{~S}$ rDNA and COI, but apart from the lack of a Zoanthidae outgroup, there were some other small but noticeable differences (Fig. 4). Foremost, the tree showed good resolution, with all species groups forming clear clades with relatively high (e.g. ML $>75 \%$ ) bootstrap support. The Palythoa heliodiscus group was seen to be most distant from other species, followed by the very-well supported $S$. marsupialis group $(\mathrm{NJ}=100 \%, \mathrm{ML}=99 \%$, Bayes $=$ $1.00)$, which was sister to a well supported ( $\mathrm{NJ}=100 \%$, $\mathrm{ML}=100 \%$, but Bayes $=0.50) P$. sp. 'sakurajimensis' + P. mutuki + P. tuberculosa $+P$. sp. 'yoron' sensu Reimer et al. (2007b) + P. caribeaoreoum clade. In the Bayesian analyses, the $P$. heliodiscus subclade (Bayes $=1.00)$ and the Sphenopus subclade $($ Bayes $=1.00)$ were sister $($ Bayes $=1.00)$ and within a $P$. mutuki $+P$. tuberculosa $+P$. sp. 'yoron' + P. caribeaoreoum clade. The $S$. marsupialis clade of five sequences had some variation between individual sequences $(59 / 905$ base pairs $=6.5 \%$ ), particularly in the spacers ITS1 and ITS2, but similar or higher levels of ITS-rDNA sequence variation have previously been observed within other Sphenopidae species (Palythoa, see Reimer $e t$ al., 2007b).

\section{Ancestral character state reconstruction}

Both ML and MP analyses very strongly indicated that colonial and zooxanthellate character states were ancestral in Sphenopidae (ML proportional likelihood $=$ 


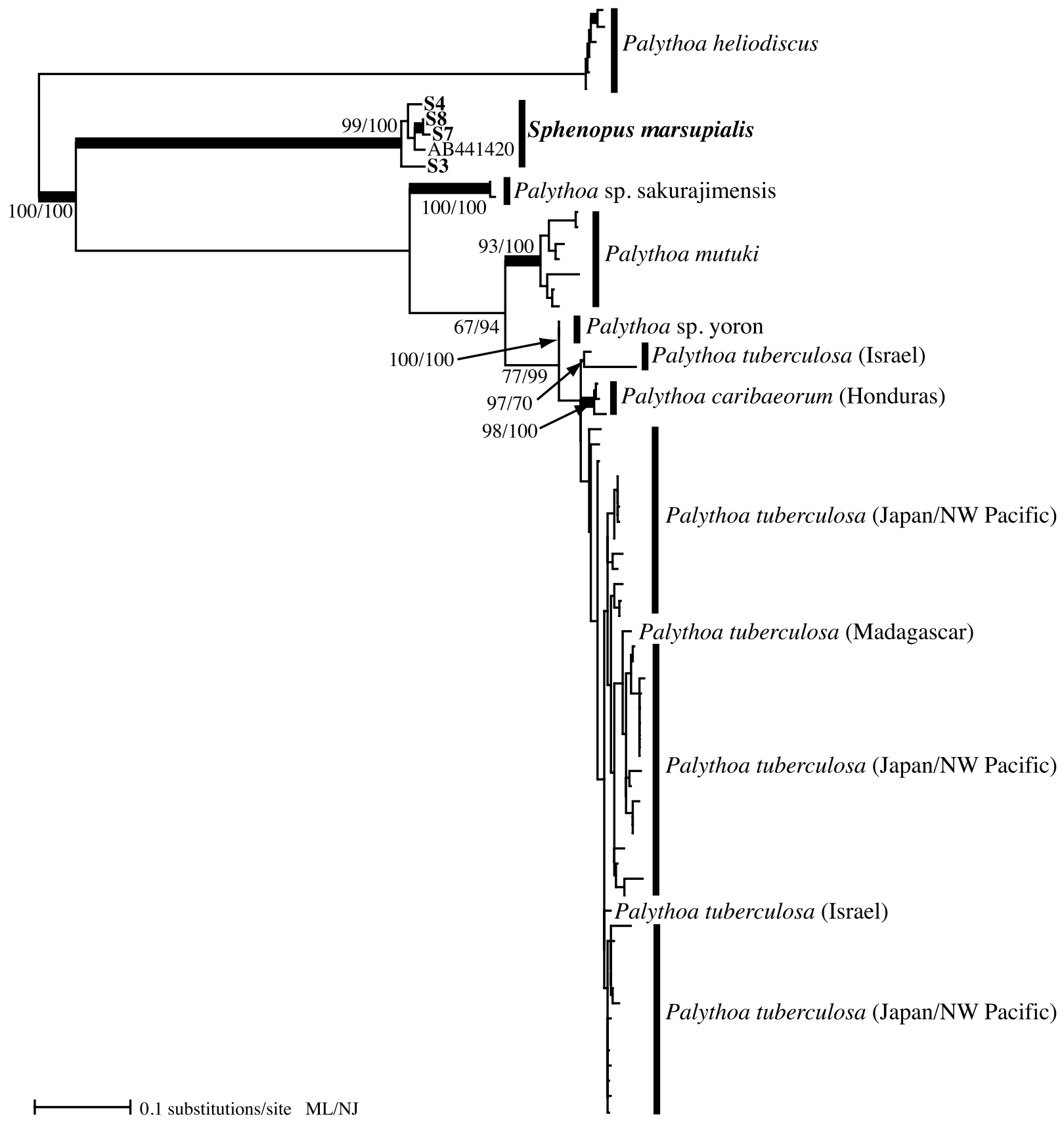

Fig. 4. Maximum likelihood (ML) tree of an alignment of nuclear internal transcribed spacer region (18S, ITS-1, 5.8S, ITS-2, 28S) ribosomal DNA sequences for zoanthid specimens. Values at branches represent ML and neighbor-joining (NJ) bootstrap values, respectively. Thick branches indicate Bayesian posterior probabilities $>0.95$. Sequences newly obtained in this study in bold. For specimen information see Table 1. 


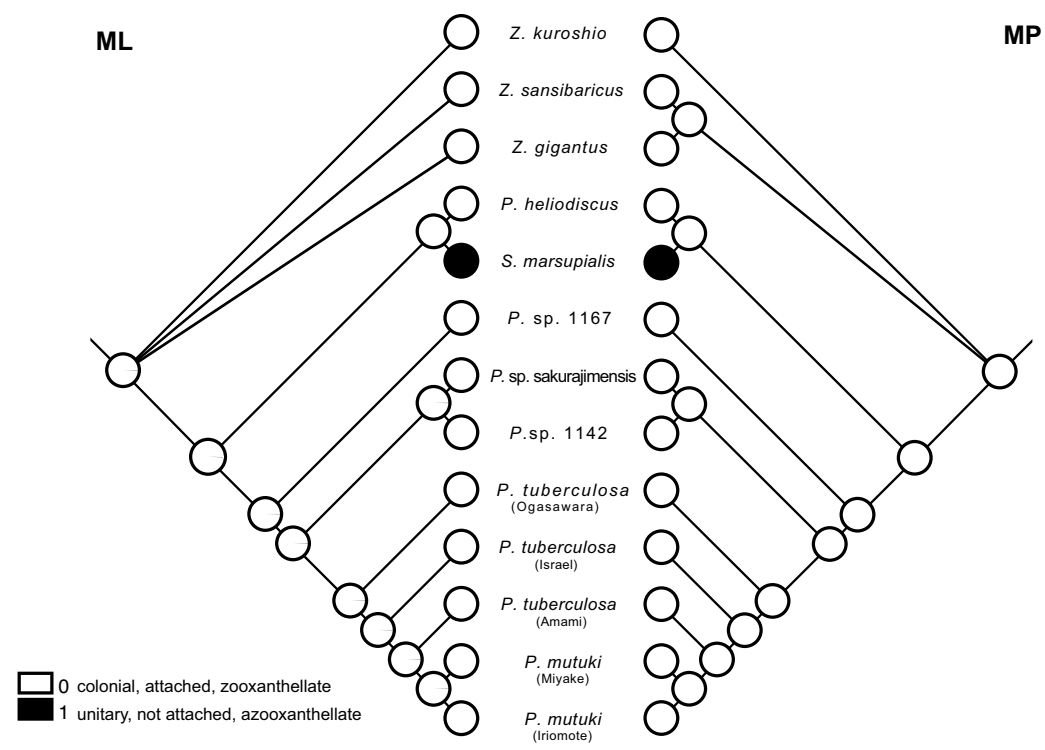

MP

Fig. 5. Ancestral state reconstruction of gross colony morphology and state of Symbiodinium (zooxanthellae) symbioses in brachycnemic zoanthids utilizing maximum likelihood (ML; left) and maximum parsimony (MP; right) methods traced on an identical ML tree of mitochondrial $16 \mathrm{~S}$ ribosomal DNA. Note that gross colony morphology and symbiosis state results gave identical results.
0.994-1.000 for all internal nodes), and that S. marsupialis alone has uniquely evolved into a unitary, freeliving and azooxanthellate state (Fig. 5).

\section{Discussion}

From the phylogenetic results of this study, Sphenopus is unequivocally within the Palythoa generic level clade (Figs 2-4), and even shares identical COI sequences with Palythoa tuberculosa. From these unexpected results, several conclusions can be drawn.

First, these results demonstrate that short ( $460 \mathrm{bp}$ ) COI sequences alone are not enough to distinguish all zoanthid species from one another. Thus, any 'DNA barcoding'-type of identification of zoanthids should utilize additional mt 16S rDNA sequences, as suggested in Sinniger et al. (2008). Furthermore, these results demonstrate the slow evolution of mt DNA in Anthozoa, as previously suggested (Shearer et al., 2002; Huang et al., 2008). On the other hand, these results demonstrate that any difference(s) in mt DNA sequences between zoanthid specimens is likely indicative of a species-level difference.

Secondly, the combined phylogenetic and ancestral state reconstruction results demonstrate that changes in gross morphology (e.g. body shape, colonial/unitary, etc.) and ecology (attached/free-living, zooxanthellate/azooxanthellate) can evolve with rapidity within brachycnemic zoanthids (Fig. 5). From the present analyses, it appears that Sphenopus has made a switch from the ancestral state (colonial, attached, zooxanthellate) in the Palythoa clade to a unitary, freeliving, azooxanthellate mode of life. While we did not calculate a molecular clock time for the divergence between Sphenopus and its closest Palythoa relative (P. tuberculosa), the topology of the three DNA marker trees and previously estimated rates of anthozoan DNA evolution (Medina et al., 2006) indicate that the switch undoubtedly occurred within recent evolutionary history. In this context it is notable that a recent molecular study of mushroom corals (Scleractinia: Fungiidae) shows that evolutionary switches in morphology occur within clades, in this case from a freeliving mode of life towards attached and encrusting growth forms, and that such changes are more common than expected (Gittenberger et al., 2011; Benzoni et al., subm.). Phylogenetic reconstructions of the Fungiidae indicate that the overall morphology (habitus) of corals can change rapidly while similarity in microstructures of the coral skeleton are more consistent within evolutionary lineages (Hoeksema, 1991; Gittenberger et al., 2011). In zoanthids, Sphenopus is the only extant group that has taken the evolutionary path to an unattached mode of life, and apparently very recently in evolutionary terms.

The switch from a modular to solitary body plan is another character state transformation unique to Sphenopus among zoanthids. Although Sphenopus polyps are relatively large compared to those in Palythoa, by being solitary the whole body size as compared to encrusting forms appears more constrained. A small 
body size allows Sphenopus individuals to live partly buried in sand or on top of it, apparently enabling some degree of mobility and a subsequent capacity to shed sediments, as seen in free-living mushroom corals (Hoeksema, 1988; Bongaerts et al., 2012). The mushroom coral family Fungiidae shows several evolutionary lineages with trends from solitary (monostomatous) to modular (polystomatous) coral shapes (Hoeksema, 1991; Gittenberger et al., 2011; Benzoni et al., subm.). The smallest free-living solitary mushroom coral species (several Cycloseris spp.) are most abundant on sandy substrates and have been found co-occurring with Sphenopus individuals in the Spermonde Archipelago, South Sulawesi (Hoeksema, pers. obs.). These Cycloseris corals can maintain a small body size and perform asexual reproduction by fragmentation through autotomy (Hoeksema and Waheed, 2011). In contrast, some other Cycloseris species appear to be polystomatous and encrusting (Gittenberger et al., 2011; Benzoni et al., subm.). The largest mushroom coral species, either free-living or attached, are all polystomatous and occur on solid substrates (Hoeksema, 1991; Gittenberger et al., 2011), although some of them may also use fragmentation for reproduction and dispersal (Hoeksema and Gittenberger, 2010). Even if the evolutionary development from modular to solitary growth forms appears less common among anthozoans than the reverse, among zoanthids it is most likely connected to the colonization of sandy habitats.

Thus, the unexpected phylogenetic position of Sphenopus despite its unique body plan leads to the question of what a zoanthid genus encompasses. For obvious reasons, it is desirable to keep Sphenopus as a valid genus separate from the Palythoa clade, yet this does not reflect phylogeny and evolution. The traditional image of Palythoa being colonial and zooxanthellate may not be correct as additional, undescribed, azooxanthellate Palythoa species from coral reef caves have been found in Okinawa (Reimer, 2010), and it appears this genus encompasses a much wider diversity of lifestyles and ecologies than previously thought. A re-examination of Palythoa and its generic definition is obviously needed to reconcile taxonomy and nomenclature with the data presented here. Despite very different gross morphologies and ecologies, Sphenopus and Palythoa do have many common features, including: 1) being brachycnemic and having sand encrustation in the mesoglea, 2) having zoanthella (not zoanthina) larvae, and 3) lacking b-mastigophore nematocysts (Ryland and Lancaster, 2003). Thus, a future merging of these genera after additional confirmation is not as far-fetched as it may initially seem.

An analogy exists among mussels (Mytilidae) boring in live corals. While shells of species classified with Leiosolenus, which live as endosymbionts in a wide range of host corals, are more or less cylindrical and torpedo-shaped, those belonging to Fungiacava, exclusively boring in mushroom corals (Fungiidae), are typically flat and heart-shaped. Although based on molecular evidence Fungiacava is part of the Leiosolenus clade, its unique shell shape and host specificity justify its status as a separate genus (Owada and Hoeksema, 2011).

The results of this study resemble other recent phylogenetic results in which it was seen that the rediscovered zoanthid genus Neozoanthus (Neozoanthidae) is apparently very closely related to Isaurus (Zoanthidae), calling into question the existence of Neozoanthidae as a valid family (Reimer et al., 2011a). As well, the zoanthid genus Acrozoanthus was demonstrated to be within Zoanthus (Zoanthidae), despite having a unique ecology (Reimer et al., 2011b). In contrast to the suborder Macrocnemina, in which different genera apparently have long evolutionary histories with various other organisms that they utilize as substrates (Sinniger et al., 2010), it appears that brachycnemic zoanthids, although generally restricted in distribution to shallow subtropical and tropical waters (Swain, 2010), can evolve new life history strategies and change their gross morphology relatively rapidly, allowing species to inhabit the many various microhabitats of coral reef ecosystems. It may be that the high levels of intraspecific morphological variation observed in some brachycnemic species (Burnett et al., 1994, 1995; Reimer et al., 2004) are adaptive in allowing species to diversify rapidly when encountering changes in environments.

This and other recent studies (Gittenberger et al., 2011; Owada and Hoeksema, 2011; Reimer et al., 2011a; Benzoni et al., subm.) demonstrate that in invertebrates with relatively simple and/or modular body plans morphological or ecological characters thought to be diagnostic may not always be so. Comprehensive analyses utilizing both molecular and morphological methods will allow researchers to re-assess relationships not only between zoanthids, but also in many other understudied marine invertebrate groups. At the same time, it is hoped that as an end result of such studies, the classification and identification of zoanthids can become more accessible, allowing a clearer understanding of this order of hexacorals. 


\section{Acknowledgements}

JDR was supported in part by the Rising Star Program and the International Research Hub Project for Climate Change and Coral Reef/Island Dynamics (both University of the Ryukyus). Collection of Brunei specimens was funded by a Science \& Technology Grant from the Brunei Government (grant number UBD/GSR/S\&T/14). Three anonymous reviewers' comments greatly improved the manuscript.

\section{References}

Benzoni F, Arrigoni R, Stefani F, Reijnen BT, Montano S, Hoeksema BW. subm. Phylogenetic position and taxonomy of $C y$ closeris explanulata and C. wellsi (Scleractinia: Fungiidae): lost mushroom corals find their way home. Contributions to Zoology.

Bongaerts P, Hoeksema BW, Hay KB, Hoegh-Guldberg O. 2012. Mushroom corals overcoming live burial through pulsed inflation. Coral Reefs, doi: 10.1007/s00338-011-0862-z.

Burnett WJ, Benzie JAH, Beardmore JA, Ryland JS. 1994. High genetic variability and patchiness in a common Great Barrier Reef zoanthid (Palythoa caesia). Marine Biology 121: 153-160.

Burnett WJ, Benzie JAH, Beardmore JA, Ryland JS. 1995. Patterns of genetic subdivision in populations of a clonal cnidarian, Zoanthus coppingeri, from the Great Barrier Reef. Marine Biology 122: 665-673.

Burnett WJ, Benzie JAH, Beardmore JA, Ryland JS. 1997. Zoanthids (Anthozoa, Hexacorallia) from the Great Barrier Reef and Torres Strait, Australia: systematics, evolution and a key to species. Coral Reefs 16: 55-68.

Colin PL, Arneson C. 1995. Tropical Pacific Invertebrates. Beverly Hills, CA: Coral Reef Press.

Delage Y, Hérouard E. 1901. Zoanthidés. - Zoanthidae. Pp. 654-667 in: Reinwald C, ed., Traité de Zoologie concrète. Tome II - 2e Partie. Les Coelentérés. Paris.

Den Hartog JC. 1997. The sea anemone fauna of Indonesian coral reefs. Pp. 351-370 in: Tomascik T, Mah AJ, Nontji A, Moosa MK, eds, The ecology of the Indonesian seas 1 . Singapore: Periplus Editions.

Erhardt H, Knop D. 2005. Corals - Indo-Pacific field guide. Frankfurt: IKAN Unterwasser-Archiv.

Felsenstein J. 1985. Confidence limits on phylogenies: an approach using the bootstrap. Evolution 39: 783-791.

Fukami H, Chen CA, Budd AF, Collins A, Wallace C, Chuang YY, Chen C, Dai CF, Iwao K, Sheppard C, Knowlton N. 2008. Mitochondrial and nuclear genes suggest that stony corals are monophyletic but most families of stony corals are not (order Scleractinia, class Anthozoa, phylum Cnidaria). PLoS One 3: e3222.

Gittenberger A, Reijnen BT, Hoeksema BW. 2011. A molecularly based phylogeny reconstruction of mushroom corals (Scleractinia: Fungiidae) with taxonomic consequences and evolutionary implications for growth forms and life history traits. Contributions to Zoology 80: 107-132.

Gmelin JF. 1791. Caroli a Linne Systema Naturae per regna tria naturae, secundum classes, ordines, genera, species, cum characteribus, dif ferentiis, synonymis, locis. Editio decima tertia, aucta, reformata. Lipsiae: Georg Emanuel Beer.

Guindon S, Gascuel O. 2003. A simple, fast, and accurate algorithm to estimate large phylogenies by maximum likelihood. Systematic Biology 52: 696-704.

Haddon AC, Shackleton AM. 1891. Reports on the zoological collections made in Torres Straits by Professor A.C. Haddon, 1888-1889. Actiniæ: I. Zoantheæ. Scientific Transactions of the Royal Dublin Society 4: 673-701.

Haywick DW, Mueller EM. 1997. Sediment retention in encrusting Palythoa spp. - a biological twist to a geological process. Coral Reefs 16: 39-46.

Hertwig R. 1882. Report on the Actiniaria dredged by HMS Challenger during the years 1873-1876. Report on the scientific results of the exploring voyage of HMS Challenger 1873-1876. Zoology 6: 1-122.

Hertwig R. 1888. Report on the Actiniaria dredged by HMS Challenger during the years 1873-1876. Supplement. Report on the scientific results of the exploring voyage of HMS Challenger 1873-1876. Zoology 26: 4-56.

Hoeksema BW. 1988. Mobility of free-living fungiid corals (Scleractinia), a dispersion mechanism and survival strategy in dynamic reef habitats. Proceedings of the $6^{\text {th }}$ International Coral Reef Symposium 2: 715-720.

Hoeksema BW. 1991. Evolution of body size in mushroom corals (Scleractinia: Fungiidae) and its ecomorphological consequences. Netherlands Journal of Zoology 41: 122-139.

Hoeksema BW, Gittenberger A. 2010. High densities of mushroom coral fragments at West Halmahera, Indonesia. Coral Reefs 29: 691.

Hoeksema BW, Waheed Z. 2011. Initial phase of autotomy in fragmenting Cycloseris corals at Semporna, eastern Sabah, Malaysia. Coral Reefs 30: 1087.

Huang D, Meier R, Todd PA, Chou LM. 2008. Slow mitochondrial COI sequence evolution at the base of the metazoan tree and its implications for DNA barcoding. Journal of Molecular Evolution 66: 167-174.

Kimura M. 1980. A simple method for estimating evolutionary rates of base substitutions through comparative studies of nucleotide sequences. Journal of Molecular Evolution 16: 111-120.

Klunzinger CB. 1877. Die Korallthiere des Rothen Meeres. 1: Die Alcyonarien und Malacodermen. Berlin: Gutmann'schen Buchhandlung.

Maddison WP, Maddison DR. 2010. Mesquite: a modular system for evolutionary analysis, v 2.74. Available from: http:// mesquiteproject.org.

Medina M, Collins AG, Takeoka TL, Kuehl JV, Boore JL. 2006. Naked corals: skeleton loss in Scleractinia. Proceedings of the National Academy of Science of the United States of America 103: 9096-9100.

Muirhead A, Ryland JS. 1985. A review of the genus Isaurus Gray 1828 (Zoanthidea), including new records from Fiji. Journal of Natural History 19: 323-335.

Owada M, Hoeksema BW. 2011. Molecular phylogeny and shell microstructure of Fungiacava eilatensis Goreau et al. 1968, boring into mushroom corals (Scleractinia: Fungiidae), in relation to other mussels (Bivalvia: Mytilidae). Contributions to Zoology 80: 169-178.

Pax F. 1924. Anthozoen des Leidener Museums. Zoologische Mededelingen, Leiden 8: 1-17. 
Reimer JD. 2010. Key to field identification of shallow water brachycnemic zoanthids (Order Zoantharia: Suborder Brachycnemina) present in Okinawa. Galaxea 12: 23-29.

Reimer JD. 2011. Sphenopus Steenstrup, 1856. Accessed through: World Register of Marine Species at http://www. marinespecies.org/aphia.php? $\mathrm{p}=$ taxdetails $\& i d=267847$ [visited 22 November 2011].

Reimer JD, Ono S, Takishita K, Fujiwara Y, Tsukahara J. 2004. Reconsidering Zoanthus spp. diversity: molecular evidence of conspecifity within four previously presumed species. Zoological Science 21: 517-525.

Reimer JD, Ono S, Iwama A, Tsukahara J, Takishita K, Maruyama T. 2006a. Morphological and molecular revision of $\mathrm{Zo}$ anthus (Anthozoa: Hexacorallia) from southwestern Japan with description of two new species. Zoological Science 23: 261-275.

Reimer JD, Ono S, Takishita K, Tsukahara J, Maruyama T. 2006b. Molecular evidence suggesting species in the zoanthid genera Palythoa and Protopalythoa (Anthozoa: Hexacorallia) are congeneric. Zoological Science 23: 87-94.

Reimer JD, Hirano S, Fujiwara Y, Sinniger F, Maruyama T. 2007a. Morphological and molecular characterization of Abyssoanthus nankaiensis, a new family, new genus and new species of deep-sea zoanthid (Anthozoa: Hexacorallia: Zoantharia) from a northwest Pacific methane cold seep. Invertebrate Systematics 21: 255-262.

Reimer JD, Takishita K, Ono S, Maruyama T. 2007b. Diversity and evolution in the zoanthid genus Palythoa (Cnidaria: Hexacorallia) utilizing nuclear ITS-rDNA. Coral Reefs 26 : 399-410.

Reimer JD, Takishita K, Ono S, Tsukahara J, Maruyama T. 2007c. Molecular evidence suggesting interspecific hybridization in Zoanthus spp. (Anthozoa: Hexacorallia). Zoological Science 24: 346-359.

Reimer JD, Ono S, Tsukahara J, Iwase F. 2008. Molecular characterization of the zoanthid genus Isaurus (Anthozoa: Hexacorallia) and its zooxanthellae (Symbiodinium spp). Marine Biology 153: 351-363.

Reimer JD, Nakachi S, Hirose M, Hirose E, Hashiguchi S. 2010. Using hydrofluoric acid for morphological investigations of zoanthids (Cnidaria: Anthozoa): a critical assessment of methodology and necessity. Marine Biotechnology 12: 605-617.

Reimer JD, Hirose M, Irei Y, Obuchi M, Sinniger F. 2011a. The sands of time: Rediscovery of the genus Neozoanthus (Cnidaria: Hexacorallia) and evolutionary aspects of sand en- crustation in brachycnemic zoanthids. Marine Biology 158: 983-993.

Reimer JD, Ishikawa SA, Hirose M. 2011b. New records and molecular characterization of Acrozoanthus (Cnidaria: Anthozoa: Zoanthidae) and its endosymbionts (Symbiodinium spp.) from Taiwan. Marine Biodiversity 41: 313-323.

Rodriguez F, Oliver JL, Marin A, Medina JR. 1990. The general stochiatic model of nucleotide substitution. Journal of Theoretical Biology 142: 485-501.

Ronquist F, Huelsenbeck JP (2003) Bayesian phylogenetic inference under mixed models. Bioinformatics (Oxford) 19: 1572-1574.

Ryland JS, Lancaster JE. 2003. Revision of methods of separating species of Protopalythoa (Hexacorallia: Zoanthidea) in the tropical West Pacific. Invertebrate Systematics 17: 407428.

Shearer TL, Van Oppen MJH, Romano SL, Woerheide G. 2002. Slow mitochondrial DNA sequence evolution in the Anthozoa (Cnidaria). Molecular Ecology 11: 2475-2487.

Sinniger F, Montoya-Burgos JI, Chevaldonné P, Pawlowski J. 2005. Phylogeny of the order Zoantharia (Anthozoa, Hexacorallia) based on the mitochondrial ribosomal genes. $\mathrm{Ma}$ rine Biology 147: 1121-1128.

Sinniger F, Reimer JD, Pawlowski J. 2008. Potential of DNA sequences to identify zoanthids (Cnidaria: Zoantharia). Zoological Science 25: 1253-1260.

Sinniger F, Reimer JD, Pawlowski J. 2010. The Parazoanthidae DNA taxonomy: description of two new genera. Marine Biodiversity 40: 57-70.

Soong K, Shiau YS, Chen CP. 1999 Morphological and life history divergence of the zoanthid, Sphenopus marsupialis off the Taiwanese coast. Zoological Studies 38: 333-343.

Steenstrup JJS. 1856. Sphenopus marsupialis (Gmelin). Saerskilt Aftryk. Af det Kongelige danske Videnskabernes Selkabs Forhandlinger.

Swain TD. 2010. Evolutionary transitions in symbioses: dramatic reductions in bathymetric and geographic ranges of Zoanthidea coincide with loss of symbioses with invertebrates. Molecular Ecology 19: 2587-2598.

Zann LP. 1980. Living Together in the Sea. Neptune (NJ): TFH Publications.

Received: 3 August 2011

Revised and accepted: 14 December 2011

Published online: 31 January 2012

Editor: R.W.M. van Soest 